\title{
Análise do comportamento da susceptibilidade magnética e condutividade elétrica no perfil de alteração rochoso do depósito niquelífero de Morro do Engenho, Goiás, Brasil.
}

\author{
Felipe da Mota Alves, Adolfo Barbosa da Silva, Eduardo Moussalle Grissolia, Said Abdallah, Angeval Alves de Brito e Ricardo
} Wosniak - Serviço Geológico do Brasil (SGB/ CPRM).

Copyright 2019, SBGf - Sociedade Brasileira de Geofísica.

This paper was prepared for presentation during the 16th International Congress of the Brazilian Geophysical Society held in Rio de Janeiro, Brazil, 19-22 August 2019.

Contents of this paper were reviewed by the Technical Committee of the 16th International Congress of the Brazilian Geophysical Society and do not necessarily represent any position of the SBGf, its officers or members. Electronic reproduction or storage of any part of this paper for commercial purposes without the written consent of the Brazilian Geophysical Society is prohibited.

\section{Resumo}

Variações nas propriedades físicas podem refletir diretamente o comportamento geoquímico dos minerais nas rochas. Nesse contexto, a análise petrofísica em perfis de alteração pode ser de grande valia para a industria mineral. Com o intuito de correlacionar medidas de susceptibilidade magnética e condutividade elétrica ao perfil de alteração rochoso foram realizadas medidas em porções mineralizadas de furos de sondagem do deposito niquelífero de Morro Engenho, localizado no oeste do estado de Goiás. A partir dos resultados obtidos foi possível diferenciar o horizonte laterítico do saprolítico sendo o primeiro caracterizado por altos valores de condutividade e susceptibilidade. Os métodos e equipamentos de análise se mostraram eficientes e de baixo custo, entregando respostas interessantes, que poderão ser utilizados em associação à estudos geoquímicos, para rastrear zonas favoráveis à precipitação de elementos de interesse como o níquel e cobalto.

\section{Introdução}

O níquel (Ni) é um importante elemento químico usado como matéria prima na indústria do aço (Oliveira, 1990a). Cerca de $72 \%$ dos depósitos mundiais de $\mathrm{Ni}$ advém basicamente de depósitos do tipo lateritas. Os depósitos lateríticos de $\mathrm{Ni}$ correspondem pela maior parte da produção de Ni no Brasil (Oliveira, 1990b; Oliveira et al., 1992). Além de níquel, esses tipos de depósitos podem produzir, como subproduto, o cobalto (Co), metal importante com aplicações na medicina, na industria automotiva e aeroespacial. Uma parcela dos depósitos de $\mathrm{Ni}$ brasileiros está concentrada na região oeste do Estado de Goiás e estão geneticamente relacionados às rochas da Província Alcalina de Goiás (Oliveira et al., 1992). Dentre os depósitos desta região, o presente trabalho estudou as amostras de testemunho de sonda do Morro do Engenho.

O Morro do Engenho consiste de duas elevações alongadas e com cotas topográficas de $160 \mathrm{~m}$ de altitude (Oliveira, 1990b). Os depósitos de $\mathrm{Ni}$ da região são do tipo silicatado e foram formados a partir do enriquecimento surpergênico em terrenos derivados de rochas ultramáficas (Radaelli, 2000). Trabalhos anteriores coletaram amostras de subsuperfície por meio de testemunhos de sondagem (Chaban, 1972). Os resultados das analises destas amostras foram utilizados sobretudo para definir os parâmetros de mineralização, principalmente no que diz respeito ao teor de $\mathrm{Ni}$. Mesmo com a importância do tema, poucos trabalhos são endereçados a estudar as propriedades físicas de amostras em testemunhos de sondagem na industria mineral. Tais trabalhos são relevantes, pois possibilitam a caracterização das amostras, fornecendo informações sobre os processos formadores de solo que propiciaram o enriquecimento de níquel e outros metais. Diante desta realidade, o presente trabalho analisou comportamento da suscetibilidade magnética e condutividade elétrica nas amostras do perfil de alteração rochoso do Morro do Engenho. Espera-se que os resultados obtidos possam contribuir ao conhecimento da região e incentivar o desenvolvimento de novas metodologias para estudos petrofísicos.

\section{Localização e Geologia}

A área estudada está localizada no oeste do Estado de Goiás, mais precisamente à $75 \mathrm{~km}$ à WNW da cidade de Jussara (Radaelli, 2000). O mapa da Figura 1 apresenta as principais litologias de superfície mapeadas na região de Morro do Engenho. As rochas mais antigas da área são constituídas por unidades neoproterozóicas, representadas basicamente por sequencias vulcanossedimentares, gnaisses e granitos pós-tectônicos do Arco Magmático de Goiás e metassedimentos do Grupo Cuiabá da Faixa Paraguai (Lacerda Filho et al., 2000; Radaelli, 2000). Durante as sinéclises do Paleozoico, arenitos devonianos da Bacia do Paraná foram depositados sobre as unidades citadas (Millani \& Thomaz-Filho, 2000). Durante o Cretáceo, um extenso magmatismo alcalino, possivelmente relacionado à abertura do Oceano Atlântico Sul, originou diversas intrusões de rochas máficas-ultramáficas alcalinas nas margens da Bacia do Paraná (Junqueira-Brod et al, 2002). No oeste do Estado de Goiás, essas intrusões são coletivamente conhecidas como Província Alcalina de Goiás (PAGO), com o Morro do Engenho constituindo um exemplo típico destas intrusões.

O Morro do Engenho é constituído por duas elevações alongadas sustentadas por rochas duníticas serpentinizadas, com seu núcleo sendo formado por dunitos circundados por peridotitos e piroxenitos que gradam para gabro alcalino e nefelina sienito (Oliveira, 1990b; Junqueira-Brod et al, 2002). O processo de intemperismo que tem atuado nas rochas duníticas do 
Morro do Engenho possibilitou o desenvolvimento do manto de alteração enriquecido em $\mathrm{Ni}$. $\mathrm{O}$ manto de alteração no Morro do Engenho é constituído, da base para o topo, por um horizonte saprolítico separado de um horizonte laterítico por uma camada silicatada (Fig. 2).

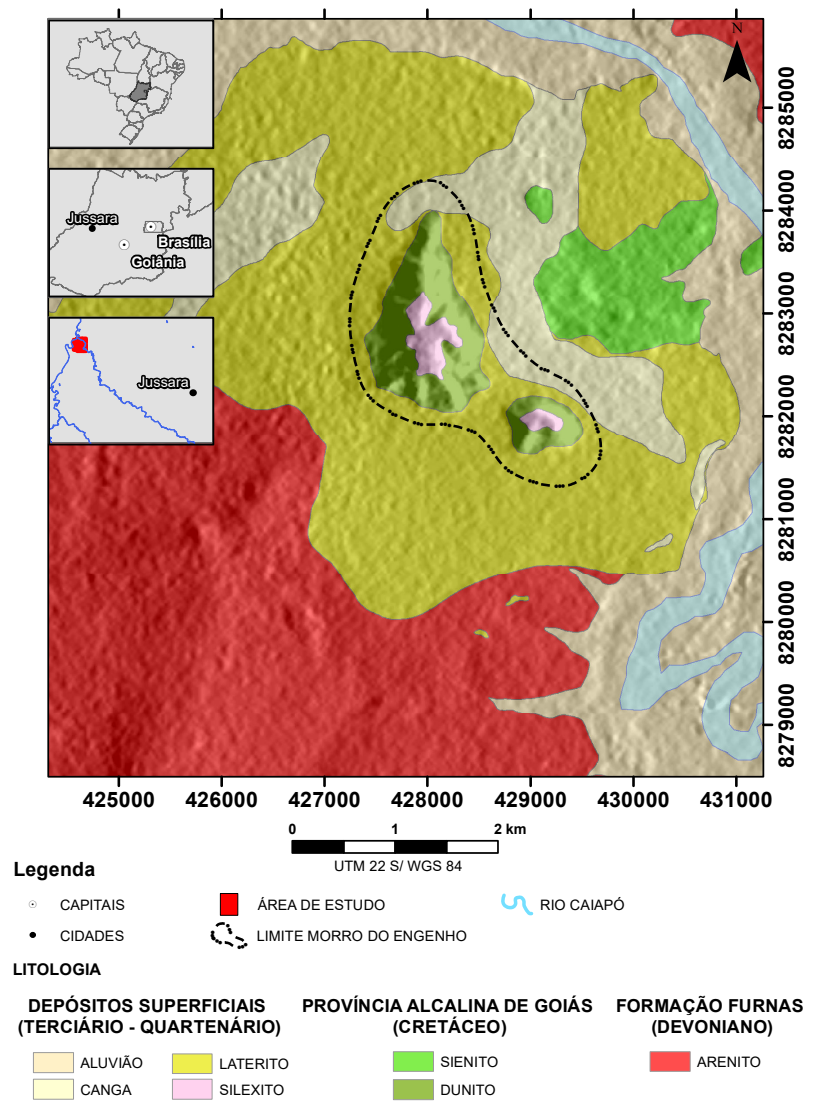

Figura 1: Mapa geológico de superfície da região de Morro do Engenho (adaptado de Chaban, 1972).

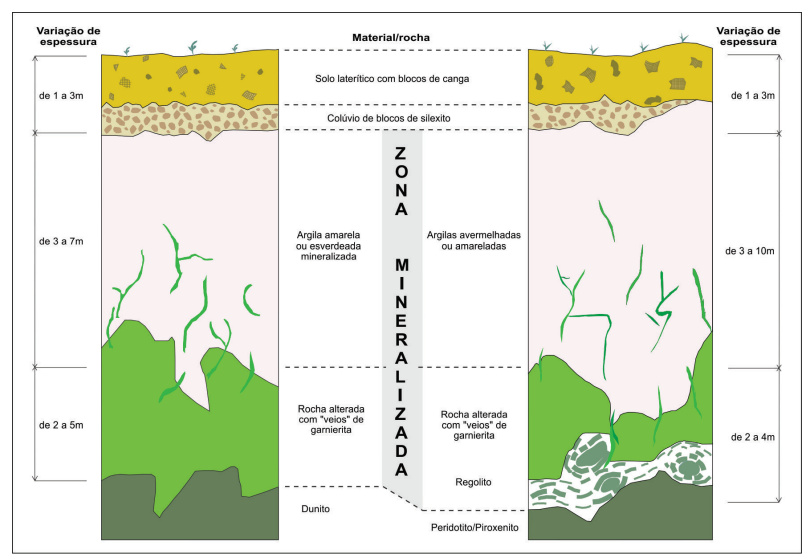

Figura 2: Perfis esquemáticos das mineralizações no depósito de Morro do Engenho (Radaelli, 2000).

Na parte basal do saprólito, a estrutura da rocha original é conservada. Em direção ao topo, a alteração do dunito produziu um aumento de material argiloso acompanhado com o aumento no conteúdo de $\mathrm{Fe}, \mathrm{Cr}$, Al e Ni. Os minerais de silicatos ferro e magnésio, serpentinas, cloritas, esmectitas são predominantes. Veios de garnierita ocorrem na camada saprolítica ou nas fissuras da rocha matriz (Chaban, 1972; Oliveira et al., 1992; Radaelli, 2000). O horizonte saprolítico é sotoposto por uma camada de colúvio de blocos silexito e por uma camada laterítica. Esta última é essencialmente ferruginosa, sendo a goetita o mineral predominante, seguido pela hematita no topo do perfil. A zona mineralizada compreende a região limitada desde a base da camada saprolítica até a base da camada silicatada. Segundo as analises de Radaelli (2000), o teor médio de Ni é de 1,34\%.

\section{Metodologia e Aplicação}

A susceptibilidade magnética é definida como a medida da resposta magnética de um material a um campo magnético externo (Hunt et al, 1995). Matematicamente, a susceptibilidade é uma propriedade adimensional $k$ que correlaciona o vetor de magnetização (M) com o vetor campo magnético (H)(Kearey et al., 2003):

$$
\mathbf{M}=k \mathbf{H} \text {. }
$$

Todos os materiais têm susceptibilidade magnética, que pode ser positiva (paramagnéticos) ou negativa (diamagnéticos). Em materiais rochosos os principais componentes minerais responsáveis por altos valores de susceptibilidade magnética são magnetitas e algumas ilmenitas e pirrotitas (Clark, 1997). A condutividade elétrica é a medida da capacidade de um material em conduzir corrente elétrica. Numericamente, podemos representar a condutividade elétrica, designada no SI em Siemens por metro, como o tensor $(\sigma)$ que correlaciona um campo elétrico $(\mathbf{E})$ a uma densidade de corrente $(\mathbf{J})$ (Telford et al., 1991):

$$
\mathbf{J}=\sigma \mathbf{E} .
$$

O processo de condução elétrica em uma rocha é complexo, além de sua composição, a presença de eletrólitos nos poros das rochas, e ainda a relação volumétrica desses poros na quantidade de rocha total, influenciam fortemente 0 processo de condução da corrente. Rochas sedimentares, assim como materiais argilosos, costumam apresentar elevada condutividade ao passo que rochas ígneas não fraturadas apresentam forte resistência a passagem de corrente elétrica, principalmente devido a baixa porosidade (Dentith \& Mudge, 2014).

Para a aquisição dos dados foi utilizado o equipamento KT10 S/C da Terraplus inc. Este aparelho fornece medidas de susceptibilidade magnética e condutividade elétrica de amostras de rocha com um bom nível de acurácia, apesar de ser um equipamento voltado para trabalhos de campo. Durante a etapa de levantamento de dados foram realizadas medidas em intervalos de interesse em 33 testemunhos de sondagem.

Devido ao grau fragmentação dos testemunhos não foi possível utilizar o modo scanner do equipamento, que permitiria a realização medidas continuas. Para transpor esta dificuldade foram feitas amostragens pontuais em intervalos com comprimentos variados, porém tentando-se manter a densidade de uma medida por metro. O processo de aquisição gerou um banco de dados com 464 amostras, totalizando aproximadamente 500 metros de testemunhos amostrados. 
Através do banco de dados formatado, correlacionamos a posição das amostras em cada furo com a descrição de campo simplificada que foi realizada por Chaban (1972), separando para este trabalho essencialmente os lateritos, argilas e o dunito (rocha fonte alterada ou semi-alterada). Para analisar o comportamento da suscetibilidade e da condutividades nas amostras, foi gerado um gráfico logarítmico de dispersão (Fig. 4) que correlaciona à descrição petrológica simplificada com as propriedades petrofísicas medidas. Esse tipo de gráfico foi escolhido devido a ampla variação dos valores resultantes. No mapa da Figura 3 os furos de sondagem e suas respectivas referências são confrontados com o mapa geoquímico de isoteores confeccionado por Chaban (1972).

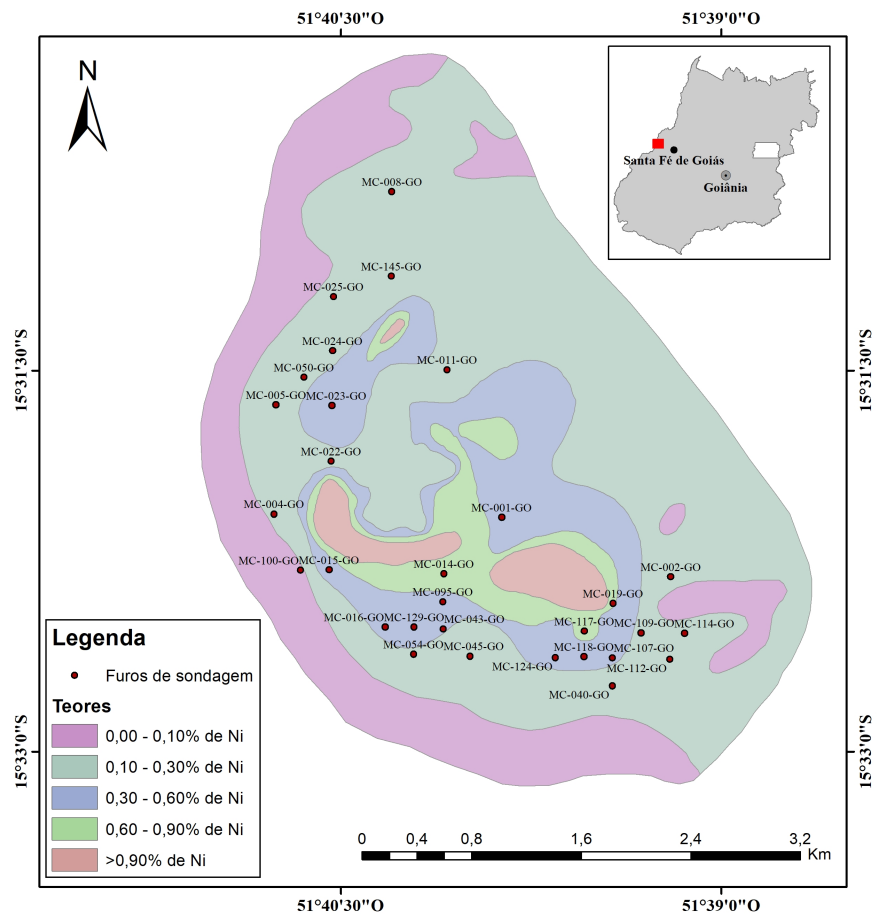

Figura 3: Posicionamento dos furos de sonda analisados e mapa geoquímico com os isoteores de níquel encontrados na área.

\section{Resultados}

Em uma primeira análise é possível perceber no grafico da Figura 4 que quase a totalidade das amostras apresentam susceptibilidade magnética significativa, maior que $0,125 \times 10$ e-3 SI. Tal comportamento já era esperado visto que as amostras são fruto da alteração de uma rocha ultramáfica, composta predominantemente por minerais ferromagnéticos.

Quando compilamos os dados é possível observar que os lateritos apresentam alta susceptibilidade magnética e condutividade elétrica, ocupando uma zona definida no quadrante direito superior do gráfico (Fig 4). As argilas, por sua vez, possuem um comportamento errático, se espalhando por diversas zonas. Já as amostras classificadas como a rocha fonte, se apresentam predominantemente na região central do gráfico da Figura 4.

Através do posicionamento das amostras no gráfico da Figura 4, foi possível agrupar os dados em duas zonas bem definidas, ambas com formato elíptico. A primeira zona apresenta excentricidade próxima de um, agrupando grande parte das amostras de laterita. Essa zona é caracterizada principalmente por uma tendência linear representativa e altos valores de susceptibilidade magnética e condutividade elétrica, sendo denominada de zona das lateritas. A segunda zona ocupa a região central do gráfico e apresenta excentricidade próxima de zero (formato quase circular), concentrando as amostras do aglomerado rochoso dunítico alterado. Nessa última região exibida os valores petrofísicos medidos são mais suaves quando comparamos com a zona das lateritas.

\section{Discussões e Conclusões}

O comportamento magnético relevante das lateritas pode ser explicado pelo processo de alteração química, que ataca alguns minerais liberando íons de ferro, que são oxidados, precipitando-se na forma hidróxidos, e posteriormente perdem água, transformando-se em óxidos como a hematita. A maghemita por sua vez é um óxido metaestável resultante intermediário da transformação de magnetita em hematita, que apresenta alta susceptibilidade magnética (Mullins, 1977). A atitude condutiva do material laterítico pode ser interpretado pelo acumulo, naquela zona do perfil de alteração, de elementos bons condutores (como ferro, cromo e cobalto) e/ou pelo aumento da porosidade com consequente retenção de umidade no material. Elevações na concentração de água diminuem consideravelmente a resistência do meio a passagem de corrente elétrica.

O padrão disperso das argilas pode ser explicado pela variedade composicional do material descrito por Chaban (1972). Analisando, com equipamento de fluorescência de raios $\mathrm{X}$, o teor de elementos de interesse em algumas amostras de argila, foi possível identificar uma certa afinidade daquelas posicionadas na zona da rocha fonte, no gráfico apresentado, com teores de níquel cobalto anômalos.

Em seu trabalho, Angeli (1988) discutiu sobre a correlação e ocorrência de níquel e cobalto no perfil de alteração de maciços ultramáficos, utilizando como exemplo o comportamento do teor de elementos de interesse no regolito do maciço de Santa Cruz em Minas Gerais (Fig. 5). Para o autor, o níquel e cobalto ocorrem normalmente associados, ambos são lixiviados para a base do perfil durante o processo de alteração, porém, devido a maior afinidade do cobalto com ferro e manganês, ele se precipita antes. O complexo de óxidos e hidróxidos de manganês, ferro e cobalto é denominado asbolana.

Se extrapolarmos o modelo deposito do maciço de Santa Cruz ao depósito de Morro do Engenho, podemos correlacionar as medidas petrofísicas com zonas de maior probabilidade de ocorrência de níquel ou cobalto. Amostras de argilas enquadradas na zona da laterita, caracterizada por alta suscetibilidade magnética e condutividade elétrica, seriam mais favoráveis à mineralização de cobalto, enquanto aquelas estabelecidas na zona do dunito, caracterizado por menor suscetibilidade magnética e condutividade elétrica seriam mais propicias à mineralização de níquel. 


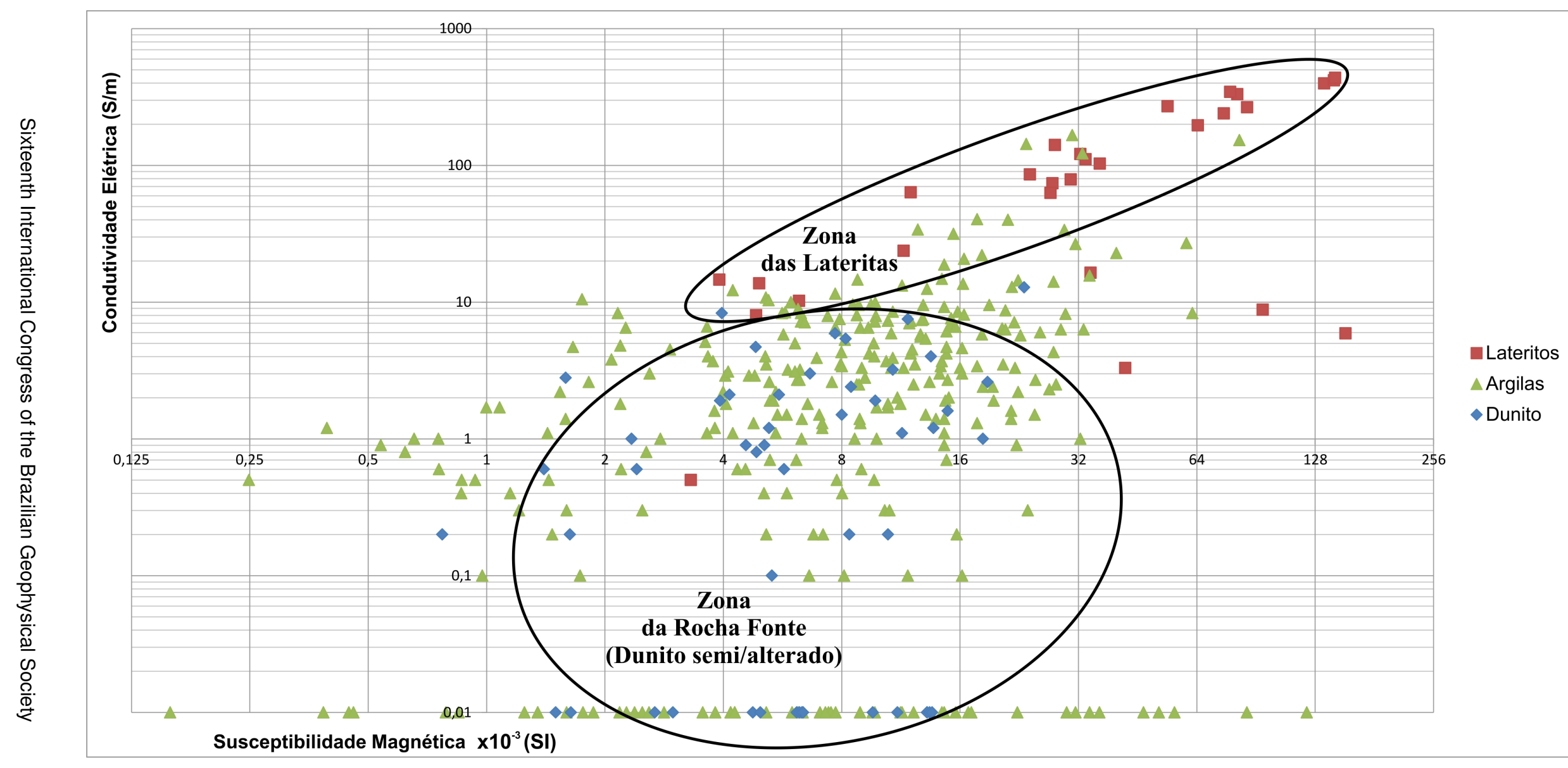

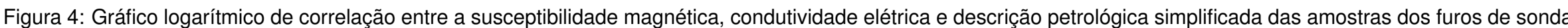
do projeto Morro do Engenho. 


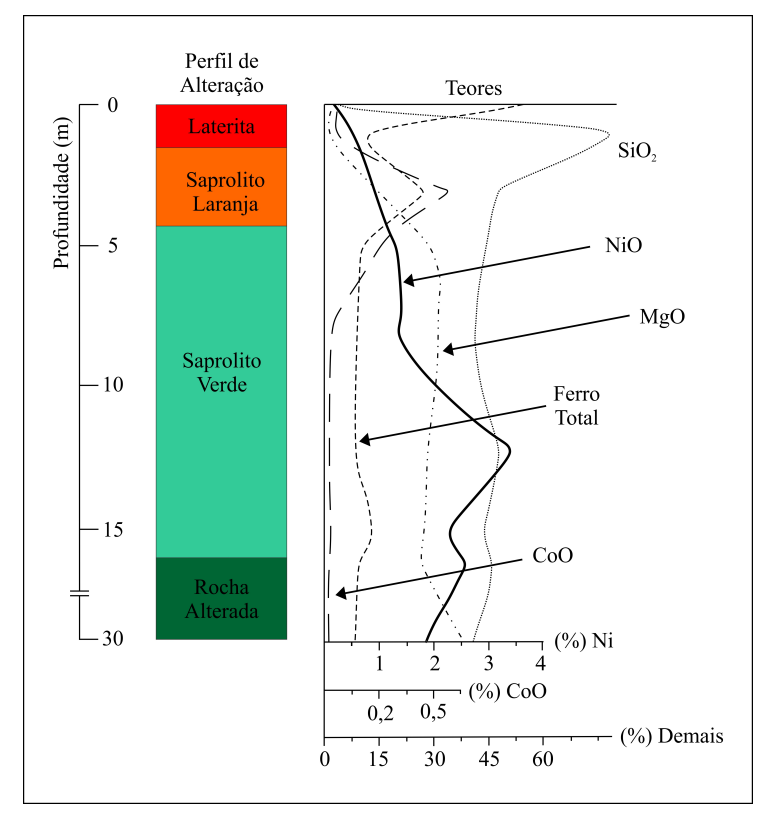

Figura 5: Modelo de perfil de alteração da extensão sul do macio de Santa Cruz - MG (adaptado de Fonte-Boa, 2017)

Com a análise dos dados obtidos foi possível distinguir de forma clara as lateritas das amostras de argilas e dunitos analisadas. Além dessa separação, a metodologia empregada se mostrou como uma alternativa para caracterizar diferentes zonas mineralizadas em níquel e cobalto no perfil de alteração do depósito. Os resultados dessa interpretação ainda devem ser refinados, assim como a técnica de aplicação melhorada, para uma maior acurácia da correlação entre os dados petrofísicos e zonas propicias a mineralização em Morro do Engenho.

\section{Agradecimentos}

Os autores agradecem ao Serviço Geológico do Brasil (SGB) pela disponibilidade dos recursos necessários para elaboração deste trabalho, em especial a Divisão de Economia Mineral e Geologia Exploratória (DIEMGE) pela liberação dos dados petrofísicos para confecção do material apresentado.

\section{Referências}

Angeli, N. (1988). Pesquisa dos Jazimentos de Níquel e Geologia da Folha Ipanema - Minas Gerais. Tese de Doutoramento. Universidade de São Paulo.

Chaban, N. (1972). Relatório de Pesquisa de Níquel na região de Morro do Engenho. Relatório Técnico. Goiânia, CPRM - Companhia de Pesquisa de Recursos Minerais.

Clark, D. A. (1997). Magnetic petrophysics and magnetic petrology: ainds to geological interpretation of magnetic surveys, Journal of Australian Geological \& Geophysical, 17(2), 83 - 103.

Dentith, M. \& Mudge, S.. (2014). Geophysics for the mineral explorations geoscientists, Cambridge University Press, $516 \mathrm{pp}$.

Fonte-Boa, T.M.R. (2017). Níquel e Cobalto. In: Soares,
A.C.P. Projeto Recursos Minerais de Minas Gerais On Line.

Hunt, C. P.; Moskowitz, B. M. \& Banerjee, S. K. (1995). Magnetic Properties of Rocks and Minerals. In: Ahrens, T.J. (Ed.), Rock Physics and Phase Relations. A Handbook of Physical Constants. American Geophysical Union, pp. 189-204.

Junqueira-Brod, T.C.; Roig, H.L.; Gaspar, J.C.; Brod, J.A. \& Meneses, P.R. (2002). A Província Alcalina de Goiás e a extensão do seu vulcanismo kamafugítico. Revista Brasileira de Geociências 32, 559-566.

Kearey, P.; Brooks, B. \& Hill, I. (2003). An introduction to geophysical exploration, Third Edition, Blackwell Science, $281 \mathrm{pp}$.

Lacerda Filho, J. V.; Rezende, A. \& Silva, A. (2000). Programa de Levantamentos Geológicos Básicos do Brasil. Geologia e Recursos Minerais do estado de Goiás e do Distrito Federal. escala 1:500000 (mapa) $2^{\circ}$ Edição.CPRM/METAGO/UnB, pp. 184.

Milani, E. J. \& Thomaz-Filho, A. (2000). Sedimentary basins of South America. Pp. 389?449. In: Cordani, UG et al.(Eds). Tectonic evolution of South America. 31st International Geological Congress. Rio de Janeiro, Academia Brasileira de Ciências e Departamento Nacional da Produção Mineral (DNPM), 856p.

Mullins, C. E. (1977). Magnetic Susceptibility of the Soil and its Significance in Soil Science - A Review.

Oliveira, S. M. B. (1990a). Estágio Atual do Conhecimento a cerca do Minério Laterítico de Níquel no Brasil e no Mundo. Rev. IG, São Paulo, 11(2), 49-57.

Oliveira, S. M. B. (1990b). Os Depósitos de Níquel Laterítico do Brasil. Universidade de São Paulo, tese de livre-docência.

Oliveira, S. M. B.; Trescases J. J. \& Melfi A. J. (1992). Lateritic nickel deposits of Brazil. Mineralium Deposita 27, 137-146.

Radaelli, V. A. (2000). Níquel do Morro do Engenho Estado de Goiás. Informe de Recursos Minerais. Goiânia, CPRM - Companhia de Pesquisa de Recursos Minerais.

Telford, W. M.; Geldart, L. P. \& Sheriff, RE. (1991). Applied Geophysics, Cambridge Univerty press. 770 pp. 